\title{
Temporal and spatial variation of the surface albedo of Morteratschgletscher, Switzerland, as derived from 12 Landsat images
}

\author{
E. J. (Lisette) KLOK, Wouter GREUELL, Johannes OERLEMANS \\ Institute for Marine and Atmospheric Research, Utrecht University, Princetonplein 5, 3584 CC Utrecht, The Netherlands \\ E-mail: e.j.klok@phys.uu.nl
}

\begin{abstract}
This investigation uses Landsat images from 12 days in 1999 and 2000 to study the spatial and temporal variation in surface albedo of a glacier with a rugged topography: Morteratschgletscher, Switzerland. Our retrieval method considers all processes that substantially influence the relationship between the satellite signal and the surface albedo. The correction for the anisotropy of the reflected radiation field of ice and snow ranges up to 0.10 , depending on wavelength band, solar zenith angle and surface type. We analyzed the uncertainties in the retrieval method and mainly expect errors in satellite-derived albedos for areas with large variation in topography and high albedos. The latter is due to application of bidirectional reflectance distribution function (BRDF) parameterizations for the anisotropic correction to albedos outside the parameterizations' validity. On average, satellite-derived albedos exceed the measured surface albedo by 0.03 . The glacier tongue is characterized by bands of low and high albedo, relating to ice with higher and lower concentrations of debris. The ice albedo shows no dependence on altitude, except at 2000-2200 m a.s.l. It increases during summer, which is likely associated with rainfall, as concluded from a comparison between summer rainfall and measured albedos.
\end{abstract}

\section{INTRODUCTION}

Net shortwave radiation is generally an important energy source for the melting process of glaciers. Therefore, glacier melt rates depend largely on the spatial and temporal variation of the surface albedo, which is the fraction of the incoming solar irradiance that is reflected by the surface. Albedo parameterizations used in energy- and massbalance models are often inadequate to represent the changes in the surface albedo in space and time and are consequently regarded as a major source of errors (e.g. Arnold and others, 1996; Klok and Oerlemans, 2002). Better knowledge of the variations in glacier albedo is needed to improve the current albedo parameterizations and massbalance models.

Various research groups have examined spatial and temporal variations in glacier albedo from field measurements and satellite images. Brock and others (2000) measured the changes in albedo across Haut Glacier d'Arolla, Switzerland, during two ablation seasons and developed a new albedo parameterization scheme. Koelemeijer and others (1993) were among the first to use satellite data to investigate the distribution of glacier albedo and its temporal evolution. They studied Landsat images of Hintereisferner, Austria. Knap and Oerlemans (1996) and Greuell (2000) used satellite images to look at the spatial and temporal variation in albedo over West Greenland. Knap and others (1999a) did a similar study for Haut Glacier d'Arolla, Switzerland; Reijmer and others (1999) and De Ruyter de Wildt and others
(2002) for Vatnajökull, Iceland; and Stroeve and others (1997) for the Greenland ice sheet. These studies used either Landsat 5 Thematic Mapper (TM) or Landsat 7 Enhanced Thematic Mapper Plus (ETM+) data with a spatial resolution of $30 \mathrm{~m}$, or U.S. National Oceanic and Atmospheric Administration (NOAA) Advanced Very High Resolution Radiometer (AVHRR) data with a resolution of $1 \mathrm{~km}$.

The authors of these papers applied different methods to derive the surface albedo from the satellite data and made different assumptions. For instance, while Koelemeijer and others (1993) did not correct for the slope of the surface, Knap and others (1999a) did, but neglected the effect of elevation on the atmospheric correction, which, according to $\mathrm{Li}$ and others (2002), must be considered in rugged mountainous areas. Often, the two-stream radiative model based on Slingo and Schrecker (1982) or the 6S radiative-transfer model (Vermote and others, 1997) was used to accomplish the atmospheric correction. Stroeve and others (1997) concluded that uncertainties in the aerosol amounts, in particular, affect the accuracy of this correction and can alter the derived albedo by 0.02. In contrast, Knap and others (1999a) stated that the atmospheric correction caused only minor errors in the derived albedo $(<0.01)$. They did not include aerosols in the radiative-transfer model and hypothesized that the role of aerosols is limited because aerosol emission sources are far away from this glacier at high elevations. Stroeve and others (1997) and De Ruyter deWildt and others (2002) were the only ones who corrected for the anisotropic nature of the reflected-radiation field of snow. 
Overall, omitting this correction is regarded as a major source of error. For example, Greuell and De Ruyter de Wildt (1999) estimated that for melting glacier ice, the mean albedo in TM band 2 increases by $0.10-0.12$ and in TM band 4 by $0.11-0.12$ after correction for anisotropy. This was calculated from a TM image of Breiðamerkurjökull, Iceland, with a solar zenith angle of $54^{\circ}$. To our knowledge, no attempt has yet been made to derive a glacier's albedo from satellite data while taking into account the anisotropy of both ice and snow.

The aim of the present work was to investigate the spatial and temporal variation of the surface albedo of a glacier. To achieve this, we studied a large series of Landsat data. The results are of interest for the modelling of spatial and temporal albedo changes within energy- and mass-balance models.

We derived surface albedos from 12 Landsat-5 TM and Landsat-7 ETM+ images of Morteratsch- and Persgletscher (together called Morteratschgletscher; see Fig. 1), southeast Switzerland $\left(46^{\circ} 24^{\prime} \mathrm{N}, 8^{\circ} 02^{\prime} \mathrm{E}\right)$. This constitutes a tough test as this glacier has a very steep and rugged accumulation zone. Morteratschgletscher's surface area is about $17 \mathrm{~km}^{2}$ and its current length is $7 \mathrm{~km}$. Its elevation ranges from 2000 to $4000 \mathrm{~m}$ a.s.l. The glacier mainly faces north and is surrounded by high mountains.

We aimed to retrieve surface albedos while taking into account all important processes that influence the relationship between the satellite signal and the surface albedo (e.g. the role of aerosols in the atmosphere). Besides, we considered the topographic effects on direct and diffuse radiation, the reflected radiation from the surrounding terrain and the anisotropic nature of the reflection pattern of ice and snow.

In this paper, we explain the retrieval method (section 2) and discuss its uncertainties (section 3). The spatial and temporal variations in the satellite-derived surface albedo of Morteratschgletscher are presented and interpreted in section 4. The Institute for Marine and Atmospheric Research, Utrecht University (IMAU), operates three automatic weather stations on Morteratschgletscher (M1-M3; see Fig. 1) and we describe a comparison of the satellite-derived albedos with ground measurements at M1. Section 5 contains a summary and the conclusions.

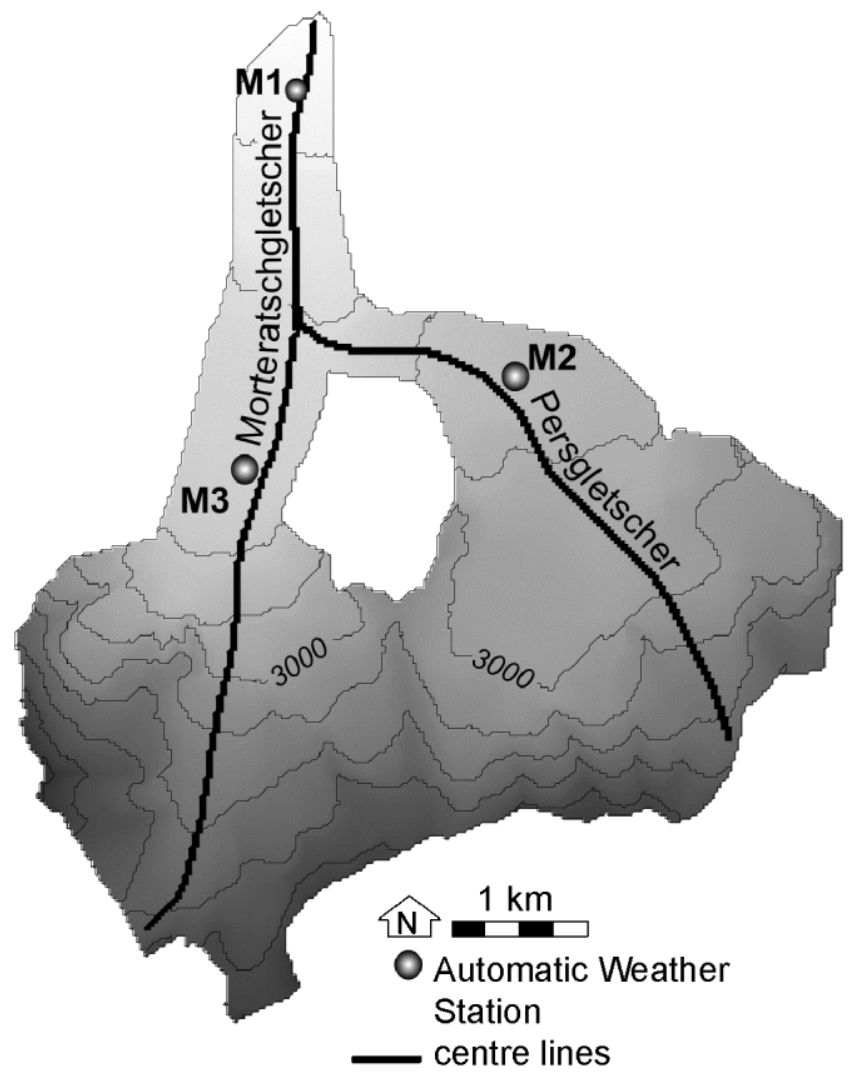

Fig. 1. Map of Morteratsch-and Persgletscher, showing the locations of the automatic weather stations and the centre lines of the glaciers. The height contours are marked every $200 \mathrm{~m}$.

\section{RETRIEVAL METHOD}

The 12 images, TM and ETM+ quarter-scenes, that we chose were taken during cloudless days in spring, summer and autumn in 1999 and 2000 (Table 1). Observations at two Meteo Schweiz synoptic stations (Robbia and Samedan) close to Morteratschgletscher confirmed that the weather conditions were cloud-free during the overpasses. First, we cut out $750 \times 750$ pixel sub-images of Morteratschgletscher

Table 1. Dates, Landsat system and solar zenith angle of the 12 Landsat images, the percentage of glacier pixels omitted because of shading, saturation in band 4 or a solar zenith angle relative to the surface exceeding $66^{\circ}$, and the total percentage omitted. The percentage of pixels with an albedo of 0.95 and of pixels saturated in band 2 is also given

\begin{tabular}{|c|c|c|c|c|c|c|c|c|}
\hline \multirow[t]{3}{*}{ Date } & \multirow[t]{3}{*}{ Landsat 5 or 7} & \multirow[t]{3}{*}{$\theta$} & \multicolumn{3}{|c|}{ Glacier satellite pixels omitted due to } & \multirow{3}{*}{$\begin{array}{c}\text { Total pixels omitted } \\
\qquad \\
\%\end{array}$} & \multirow{3}{*}{$\begin{array}{c}\text { Pixels with } \\
\text { albedo } \alpha=0.95 \\
\%\end{array}$} & \multirow{3}{*}{$\begin{array}{c}\text { Pixels saturated in } \\
\text { band } 2 \\
\%\end{array}$} \\
\hline & & & \multirow{2}{*}{$\begin{array}{c}\text { shading } \\
\%\end{array}$} & $\begin{array}{c}\text { band } 4 \\
\text { saturated }\end{array}$ & \multirow{2}{*}{$\begin{array}{c}\theta_{\mathrm{s}}>66^{\circ} \\
\%\end{array}$} & & & \\
\hline & & & & $\%$ & & & & \\
\hline 13 March 1999 & 5 & $54^{\circ}$ & 37 & 1 & 20 & 58 & 47 & 2 \\
\hline 26 July 1999 & 5 & $34^{\circ}$ & 6 & 0 & 9 & 15 & 1 & 1 \\
\hline 13 September 1999 & 7 & $45^{\circ}$ & 19 & 2 & 19 & 40 & 1 & 9 \\
\hline 15 October 1999 & 7 & $56^{\circ}$ & 48 & 2 & 20 & 70 & 6 & 51 \\
\hline 8 April 2000 & 7 & $43^{\circ}$ & 15 & 3 & 16 & 34 & 46 & 96 \\
\hline 9 May 2000 & 5 & $35^{\circ}$ & 7 & 3 & 10 & 20 & 11 & 12 \\
\hline 27 June 2000 & 7 & $28^{\circ}$ & 3 & 2 & 8 & 13 & 6 & 69 \\
\hline 21 July 2000 & 5 & $33^{\circ}$ & 6 & 2 & 9 & 17 & 6 & 10 \\
\hline 21 August 2000 & 7 & $39^{\circ}$ & 11 & 0 & 13 & 24 & 0 & 26 \\
\hline 24 October 2000 & 7 & $60^{\circ}$ & 61 & 2 & 20 & 83 & 1 & 10 \\
\hline
\end{tabular}


and the surrounding area from the quarter scenes. Then we geolocated these sub-images by relating five to seven groundcontrol points to Swiss map coordinates obtained from the Bundesamt für Landestopographie (1991).

The radiometric calibration was performed differently for TM and ETM+ data. For TM data, we used the spectral-radiance ranges for each band provided with the Landsat data and the calibration coefficients of Teillet and others (2001) to correct for the change in responsivity of the satellite sensors and estimate the radiance at satellite level from the raw data. The coefficients of Teillet and others (2001) are based on a radiometric cross-calibration of Landsat-5 TM with the well-calibrated Landsat-7 ETM+ data for a period in June 1999. For ETM+, we followed the NASA (2001) procedure to calculate the radiances. In contrast to TM, the reponsivity loss of ETM+ sensors is monitored by prelaunch and on-orbit calibration programmes, and changes in the responsivity are directly implemented in the data processing (NASA, 2001).

The planetary reflectance in each wavelength band, $r_{\text {pla,b }}$ was calculated following Markham and Barker (1985):

$$
r_{\text {pla }, \mathrm{b}}=\frac{\pi R_{\mathrm{b}} d^{2}}{E_{\text {sun }, \mathrm{b}} \cos \theta},
$$

where $R_{\mathrm{b}}$ is the radiance at satellite level in the considered wavelength band (subscript b), $d$ is the Earth-Sun distance in astronomical units, $\theta$ is the solar zenith angle, and $E_{\text {sun,b }}$ is the mean exo-atmospheric solar spectral irradiance in wavelength band $b$. Table 1 lists the solar zenith angle for the times at which our images were taken, which ranged between 0913 and 1001 UTC.

We applied the radiative transfer model $6 \mathrm{~S}$ (Vermote and others, 1997) to account for atmospheric interference. From $6 \mathrm{~S}$, coefficients were determined to relate the reflectance of a horizontal glacier surface for each wavelength band, $r_{\text {hor,b}}$, to the planetary reflectance, by following the relationship:

$$
r_{\text {hor,b }}=a_{0, \mathrm{~b}}+a_{1, \mathrm{~b}} r_{\text {pla,b }}+a_{2, \mathrm{~b}} r_{\text {pla,b }}^{2}+a_{3, \mathrm{~b}} r_{\text {pla,b }} z,
$$

where $z$ is the altitude ( $\mathrm{m}$ a.s.l.) and $a_{0 . .3, \mathrm{~b}}$ are the coefficients determined with $6 \mathrm{~S}$. We estimated the altitude of each pixel from a digital elevation model (DEM) by interpolating four DEM pixels surrounding each satellite pixel, using a DEM of 1996 from the Bundesamt für Landestopographie of Switzerland (resolution is $25 \mathrm{~m}$ ). The residual standard deviation of Equation (2) did not exceed 0.0011, which does not necessarily imply that the overall uncertainty in the correction for the atmospheric interference is small. We discuss this further in section 3.3. Addition of higher-order terms to the righthand side of the equation did not improve the performance of the fit. The coefficients of Equation (2), which we determined for the 12 images, revealed that the derived surface reflectance depends only slightly on altitude in spite of what Li and others (2002) argue. $r_{\text {hor,b }}$ changed by about 0.01 between 2000 and $4000 \mathrm{~m}$ a.s.l. for a planetary reflectance of 0.80 .

The coefficients depend on the wavelength band, the illumination view geometry and the atmospheric composition. The latter is defined by the total ozone amount, visibility (from which aerosol optical thickness is derived), watervapour content and aerosol composition. We estimated visibility and water-vapour content from data of a Meteo Schweiz synoptic weather station located close to Morteratschgletscher and a standard mid-latitude summer profile.
Ozone was determined within NASA's Total Ozone Mapping Spectrometer (TOMS) project. We assumed a constant aerosol composition throughout the year: $5 \%$ dust-like, $90 \%$ water-soluble and $5 \%$ soot. We estimated the effect on the atmospheric interference of not taking aerosols into account. For 21 August 2000, the planetary reflectance in band 2 would increase by $0.03-0.05$, and in band 4 by $0.02-0.03$, for surface reflectances of 0.5-1.0. Consequently, the effect of aerosols cannot be neglected for Morteratschgletscher. This is in agreement with the findings of Stroeve and others (1997).

Because Morteratschgletscher is relatively steep and surrounded by high mountains, we considered the topographic effects on the derived surface reflectance. We took into account direct and diffuse radiation and the reflected radiation coming from surrounding slopes. Firstly, the direct part of the irradiance was corrected for the surface inclination. Secondly, the diffuse radiation, which is a function of the sky hemisphere not obstructed by the surrounding mountains, was calculated using the sky view factor, $V_{\text {sky }}$ as defined by Dozier and Frew (1990). Lastly, the amount of reflected radiation from the surrounding terrain was estimated following Richter (1998). Accounting for these three radiation components, we derived the following equation to calculate the surface reflectance of a tilted surface, $r_{\mathrm{s}, \mathrm{b}}$, from the reflectance of a horizontal surface:

$$
r_{\mathrm{s}, \mathrm{b}}=V_{\text {hor, }} \frac{1}{V_{\text {sky }} f_{\text {dif }}+f_{\text {dir }} \frac{\cos \theta_{r}}{\cos \theta}+V_{\text {ter }} \overline{r_{\mathrm{s}, \mathrm{b}}}} .
$$

The terrain view factor, $V_{\text {ter }}$, was calculated after Dozier and Frew (1990). $\theta_{\mathrm{r}}$ is the solar zenith angle relative to the surface-parallel plane. We calculated this angle for each satellite pixel from four DEM pixels surrounding that satellite pixel. The direct $\left(f_{\text {dir }}\right)$ and diffuse $\left(f_{\text {dif }}\right)$ fraction of the solar irradiance was calculated from $6 \mathrm{~S} . \overline{r_{\mathrm{s}, \mathrm{b}}}$ is the average reflectance of the adjacent pixels (a box of $61 \times 61$ pixels). Three iterations were needed for the convergence of the average terrain reflectance to obtain a deviation $<1 \%$.

For isotropic reflecting surfaces, the surface reflectance calculated from Equation (3) equals the surface albedo. For ice and snow surfaces, however, the reflected radiation field is anisotropic. To account for this and calculate the surface band albedo $\left(\alpha_{\mathrm{s}, \mathrm{b}}\right)$, we divided the surface reflectance from Equation (3) by the anisotropic reflection factor, $f$ :

$$
\alpha_{\mathrm{s}, \mathrm{b}}=\frac{r_{\mathrm{s}, \mathrm{b}}}{f\left(\theta_{\mathrm{r}}, \theta_{\mathrm{v}}, \varphi\right)}
$$

where $\varphi$ is the relative view azimuth angle and $\theta_{\mathrm{v}}$ the satellite zenith angle with respect to the inclined surface. The anisotropic reflection factor depends on the illumination view geometry and is a surface-dependent function. It differs for ice and snow owing to their different surface reflection patterns. We calculated $f$ from bidirectional reflection distribution functions (BRDFs) derived for ice by Greuell and De Ruyter de Wildt (1999) and for snow by Koks (2001). Table 2 proves that a correction for anisotropy (difference between $\alpha_{\mathrm{s}, \mathrm{b}}$ and $\left.r_{\mathrm{s}, \mathrm{b}}\right)$ is important for large solar zenith angles. It also shows that the correction for anisotropy increases for larger wavelength bands and is greater for ice than for snow surfaces.

Finally, we calculated the broadband albedo from the albedo in bands 2 and 4, following the parameterization of Knap and others (1999b):

$$
\alpha=0.726 \alpha_{\mathrm{s}, 2}-0.322 \alpha_{\mathrm{s}, 2}^{2}-0.051 \alpha_{\mathrm{s}, 4}+0.581 \alpha_{\mathrm{s}, 4}^{2} .
$$


Table 2. Mean correction for anisotropy for satellite-derived albedos of Morteratschgletscher with standard deviation of the distribution for bands $2(0.53-0.61 \mu \mathrm{m})$ and $4\left(0.78^{-}\right.$ $0.90 \mu \mathrm{m})$, for snow and ice, and two days

\begin{tabular}{lcccc}
\hline Surface type & \multicolumn{2}{c}{24 fune $1999\left(\theta=30^{\circ}\right)$} & 15 October 1999 $\left(\theta=56^{\circ}\right)$ \\
& Band 2 & Band 4 & Band 2 & Band 4 \\
& & & & \\
\hline Snow & $-0.009 \pm 0.001$ & $0.019 \pm 0.036$ & $0.022 \pm 0.023$ & $0.081 \pm 0.048$ \\
Ice & $0.031 \pm 0.033$ & $0.036 \pm 0.040$ & $0.089 \pm 0.038$ & $0.099 \pm 0.037$ \\
\hline
\end{tabular}

If band 2 was saturated, we used a parameterization that depends only on the albedo in band 4 (Knap and others, 1999b):

$$
\alpha=0.782 \alpha_{\mathrm{s}, 4}+0.148 \alpha_{\mathrm{s}, 4}^{2} .
$$

We used these empirical relationships because they were established from ground-based simultaneous measurements of $\alpha_{\mathrm{s}, 2}, \alpha_{\mathrm{s}, 4}$ and $\alpha$ over different glacier surface types on the tongue of Morteratschgletscher. We expect that they estimate the broadband albedo accurately, as the residual standard deviations of Equations (5) and (6) are only 0.009 and 0.014 respectively (Knap and others, 1999b). Saturation in band 2 often occurred for the images in spring and autumn (see Table 1). Especially on 8 April 2000 and 27 June 2000, a large part of the image was saturated. Both images are from Landsat-7 ETM+, which is more often saturated in band 2 than Landsat- 5 TM because its spectral radiance range is $68 \%$ smaller than for band 2 of Landsat- 5 TM.

As mentioned, the BRDF parameterizations differ for ice and snow, but whether an area is ice or snow is not known beforehand. We solved this problem by calculating broadband albedos with both BRDF parameterizations. Then, we assumed that areas having a calculated surface albedo $<0.5$ with both BRDF parameterizations represented ice. We supposed that pixels having a calculated surface albedo $>0.5$ with both BRDF parameterizations pertained to snow. We omitted the remaining pixels unless the difference between the two values did not exceed 0.1, in which case we used the mean value. The number of pixels omitted was very small for most images: normally $<0.1 \%$. We based the threshold albedo of 0.5 to distinguish between ice and snow on albedo observations made on Morteratschgletscher by Knap and others (1999b). Surface albedos that exceeded 0.95 were set to 0.95 , which is about the highest snow albedo measured (Paterson, 1994).

We did not calculate albedos for all satellite pixels. We omitted:

Table 3. Ranges of BRDF parameterizations of ice (Greuell and De Ruyter de Wildt, 1999) and snow (Koks, 2001)

\begin{tabular}{lcccc}
\hline & \multicolumn{3}{c}{ Ice } & \multicolumn{2}{c}{ Snow } \\
& Min. & Max. & Min. & Max. \\
& & & & \\
\hline & & & & \\
Solar zenith angle & $26.4^{\circ}$ & $74.2^{\circ}$ & $15.91^{\circ}$ & $65.51^{\circ}$ \\
Albedo in band 2 & 0.197 & 0.670 & 0.742 & 0.984 \\
Albedo in band 4 & 0.155 & 0.601 & 0.654 & 0.897 \\
Broadband albedo & 0.14 & 0.50 & 0.55 & 0.74 \\
\hline
\end{tabular}




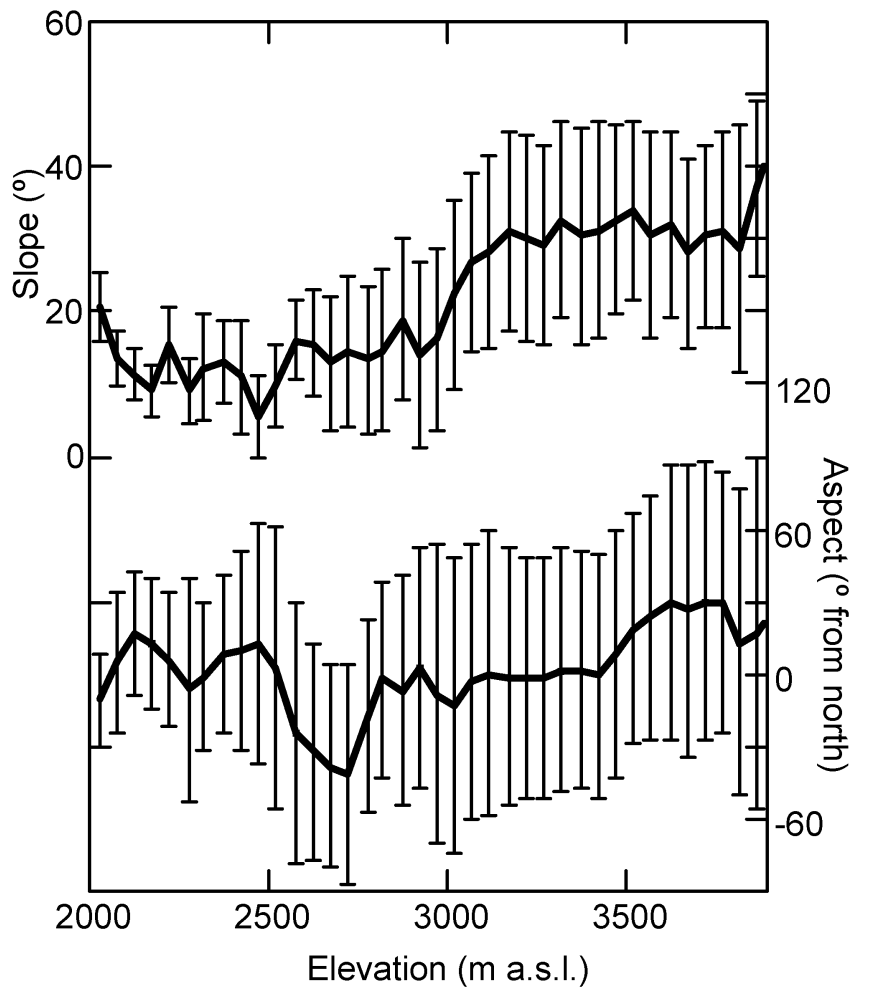

Fig. 2. Slope and aspect of Morteratschgletscher averaged over $50 \mathrm{~m}$ height intervals. The error bars indicate the standard deviation of the distribution.

errors associated with this by replacing the elevation, aspect and slope of each image pixel $(i, j)$ by the topography of its neighbouring pixel. This was done in four directions $(i \pm 1$, $j \pm 1$ ). This led to a standard deviation of 0.05 in the glacier's surface albedo. The effect was larger for altitudes $>3000 \mathrm{~m}$ a.s.l. (0.07) than for lower altitudes (0.02), which is due to the larger variation in topography at higher altitudes (see Fig. 2). Thus, the accuracy of the geolocation is important for the albedo retrieval of a single satellite pixel, but, averaged over the entire glacier, the mean change in the surface albedo is small when for each pixel the topography of the adjacent pixel is used $(<0.01)$.

\subsection{Radiometric calibration}

Usage of the appropriate set of the spectral-radiance ranges provided with each Landsat-7 ETM+ image ensures an accurate conversion to radiance units of 5\% (NASA, 2001). The coefficients that we used for the radiometric correction of Landsat-5 TM data were derived by Teillet and others (2001), who estimated the uncertainty in these coefficients at $6 \%$. Hence, we changed the coefficients for the radiometric calibration by $6 \%$ and found a standard deviation in the surface albedo of 0.02 .

\subsection{Atmospheric composition}

To estimate the uncertainty regarding the atmospheric correction, we changed some of the input values of $6 \mathrm{~S}$, namely those concerning information about the atmospheric composition. Differences in the planetary reflectance resulting from changes in the atmospheric composition were estimated as a function of the surface albedo (Fig. 3). The data of 21 August 2000 and an altitude of $2500 \mathrm{ma}$ a.s.1 defined the reference state. An increase in water vapour, ozone concentration, or a reduction in the visibility did not significantly affect the planetary reflectance. Doubling the soot concentration from $5 \%$ to $10 \%$ at the expense of water-soluble aerosols had the largest effect on the atmospheric correction. This effect is larger in band 2 because scattering by aerosols is more effective at smaller wavelengths. Changing the relative amounts of other aerosol types proved to have a negligible effect on the atmospheric correction. We estimated the impact of the uncertainty in the soot concentration on the surface albedo of Morteratschgletscher by doubling the soot. This resulted in a standard deviation of the surface albedo of 0.01 .
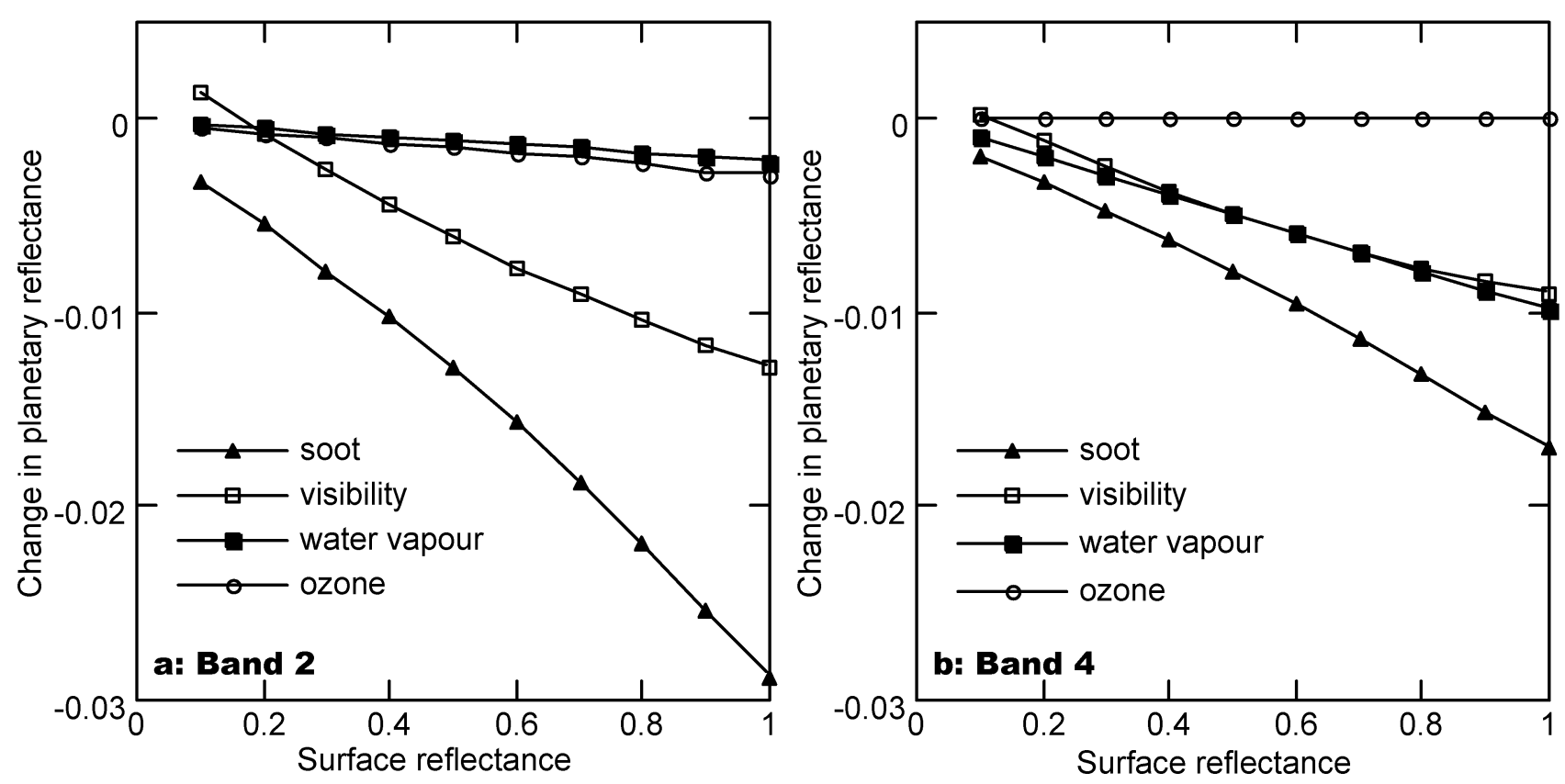

Fig. 3. Change in planetary reflectance as function of the surface reflectance for band 2 ( a) and band 4 ( $b$ ), calculated from 6S for 21 August 2000 for different changes in input parameters: increase in soot concentration from $5 \%$ to $10 \%$, decrease in visibility from $45 \mathrm{~km}$ to $30 \mathrm{~km}$, increase in water-vapour amount by $50 \%$, and increase in ozone concentration by $5 \%$. 


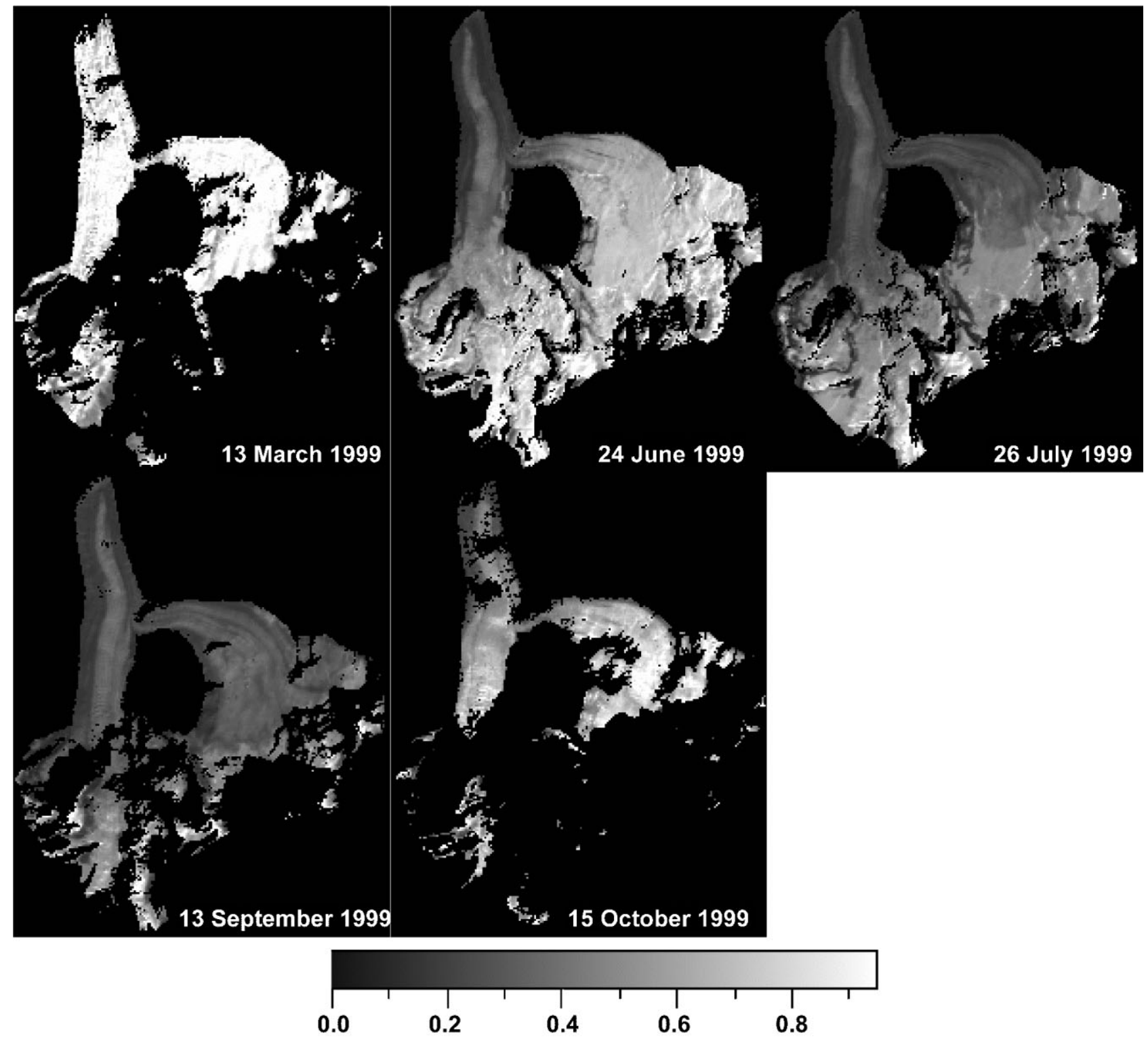

Fig. 4. Spatial distribution of Landsat-derived albedos for Morteratschgletscher for the 1999 images.

\subsection{Diffuse, direct and reflected radiation}

Uncertainties in the corrections to account for diffuse, direct and reflected radiation arise from the calculated surface topography and the appropriate parameterization for the topographic effects. We discussed the first source of error in section 3.1. Parameterizations to correct satellite imagery for topographic effects are well discussed by Proy and others (1989), Sandmeier and Itten (1997) and Richter (1998). We followed an approach similar to Richter (1998), but neglected the anisotropic contribution of the diffuse radiation. Compared to Proy and others (1989), we used a less sophisticated method to account for the terrain reflection. In order to estimate the errors involved in using a less sophisticated method, we calculated the contribution of the topographic effects for the glacier albedo of Morteratschgletscher using Equation (3).

Assuming that all radiation is direct $\left(f_{\text {dif }}=0\right)$ resulted in a standard deviation in the surface albedo of 0.02. Separating direct and diffuse radiation but not accounting for the obstruction of the sky hemisphere $\left(V_{\text {sky }}=1\right)$ led to a standard deviation of 0.01 . Neglecting the reflection from the adjacent slopes $\left(V_{\text {ter }}=0\right)$ caused a standard deviation of 0.02 .
The contributions are thus relatively small for 21 August 2000, but would be larger for areas with higher surface albedos. For example, for the areas with a surface albedo $>0.06$, exclusion of the terrain reflection resulted in a standard deviation of 0.05. Based on these results, we expect that a more sophisticated model would not change the derived surface albedo by more than 0.01 .

\subsection{BRDF parameterizations}

Table 3 shows the ranges within which the BRDF parameterizations should be applied. In spite of this, we extrapolated the BRDF parameterizations beyond these ranges regarding the surface albedo (not regarding the solar zenith angle). We also applied the BRDF parameterization of ice to areas covered with debris, for which it actually does not apply. We assumed that a correction for the anisotropy of a surface outside the range of the parameterizations would be better than applying no correction at all. The errors involved in these assumptions are unknown and are difficult to estimate because we do not know the bidirectional reflection pattern of (debris-covered) ice with very low albedos or snow with very high albedos. We expect 


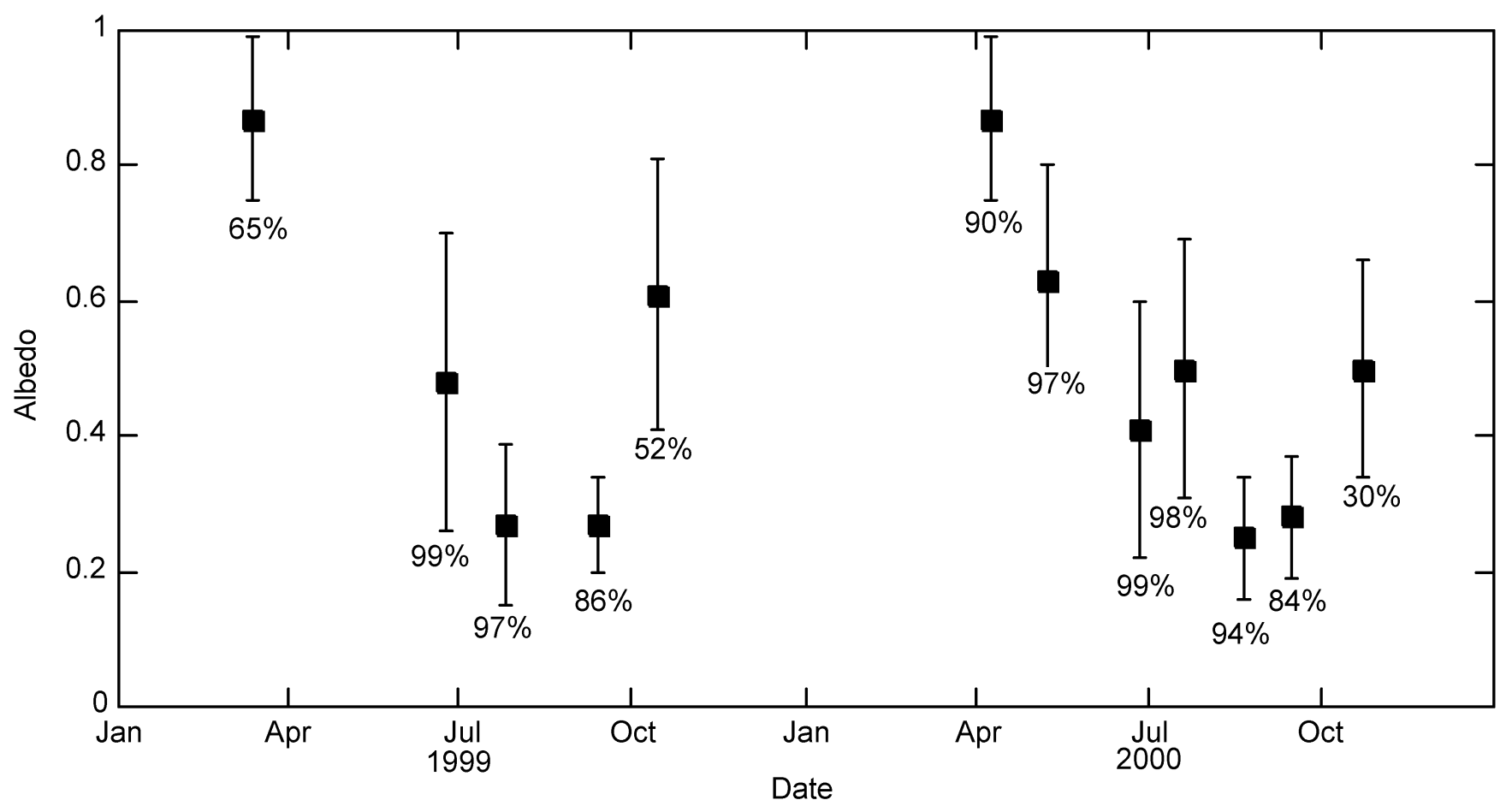

Fig. 5. Mean albedo of ablation area $(<3000 \mathrm{~m}$ a.s.l.) derived from 12 Landsat images. The error bars show the standard deviation of the distribution. The percentages indicate the fraction of pixels of the total ablation area not omitted for reasons given in Table 1.

that the error will be smaller than the magnitude of the correction. Therefore, we estimated the uncertainty in the anisotropic correction for these albedos at half the anisotropic correction. This implies 0.03 in both bands for albedos $<0.15$, and 0.01 in band 2 and 0.04 in band 4 for albedos $>0.74$. Note that these numbers were calculated from data of 21 August 2000. For days with larger solar zenith angles, the uncertainty would be larger (e.g. for 15 October 1999: 0.02 in band 2 and 0.07 in band 4 for albedos $>0.74$ ).

In addition, there are uncertainties associated with the fact that the BRDF parameterizations are based on measurements obtained at only a few locations: for ice on Morteratschgletscher (Greuell and De Ruyter de Wildt, 1999), and for snow on Glacier du Geant, Italy (Koks, 2001). These measurements were done on flat surfaces. Surface roughness, such as sastrugi, can alter the bidirectional reflectance patterns significantly (Warren and others, 1998). As the surface of Morteratschgletscher is relatively flat, we expect that this effect does not play an important role. Moreover, it is questionable if the parameterizations represent all the ice and snow surfaces of Morteratschgletscher, since they are based on measurements from only a few locations. If we assume that the error involved in this is half the anisotropic correction, it might range between 0.01 and 0.05 depending on the wavelength band, the surface type and especially the solar zenith angle (see Table 2).

\subsection{Narrow-to-broadband conversion}

The narrow-to-broadband albedo parameterizations make an accurate estimate of the broadband albedo, according to the low residual standard deviations of Equations (5) and (6), mentioned in section 2. Therefore, we also expect that the effect of saturation in band 2 does not appear to influence the calculation of the surface albedo significantly.

\section{RESULTS AND INTERPRETATION}

\subsection{Spatial distribution of the surface albedo of the entire glacier}

Figure 4 shows the derived glacier surface for five Landsat images of 1999. In March, the glacier was covered by snow. The derived surface albedo was 0.95 for $47 \%$ of the area (see also Table 1), which seems rather high. This could be ascribed to uncertainties in the correction for anisotropy because only $29 \%$ of the pixels were within the albedo ranges of the BRDF parameterization for snow (Table 3). The black areas on the tongue, visible in March and October, are steep areas where pixels were omitted because of shading.

From June to September, the area with exposed glacier ice increased. The images reveal that the glacier tongue consisted of clean glacier ice in the middle, surrounded by ice with a significantly lower albedo (0.15), owing to debris. Where glacier ice is exposed, the lateral variation in albedo appears to exceed the altitudinal variation in albedo in the ablation area. The images do not clearly indicate the position of the snowline, except for 26 July, for which a sharp transition in the surface albedo is visible on Persgletscher. Sometimes, areas with low surface albedos are found for the highest altitudes, which is not exactly what one might expect. This could be due to parts of the mountain tops not being covered with snow, but these findings also support the notion that the albedo retrieval method is not accurate for areas with a large variation in surface topography (Fig. 2).

\subsection{Albedo of the ablation area}

Figure 5 shows the mean albedo of the ablation area, defined here as the area below $3000 \mathrm{~m}$ a.s.l. The mean albedos in March and April were very high $(>0.90)$, but became small in summer. The lowest mean albedo $(0.25)$ was derived 

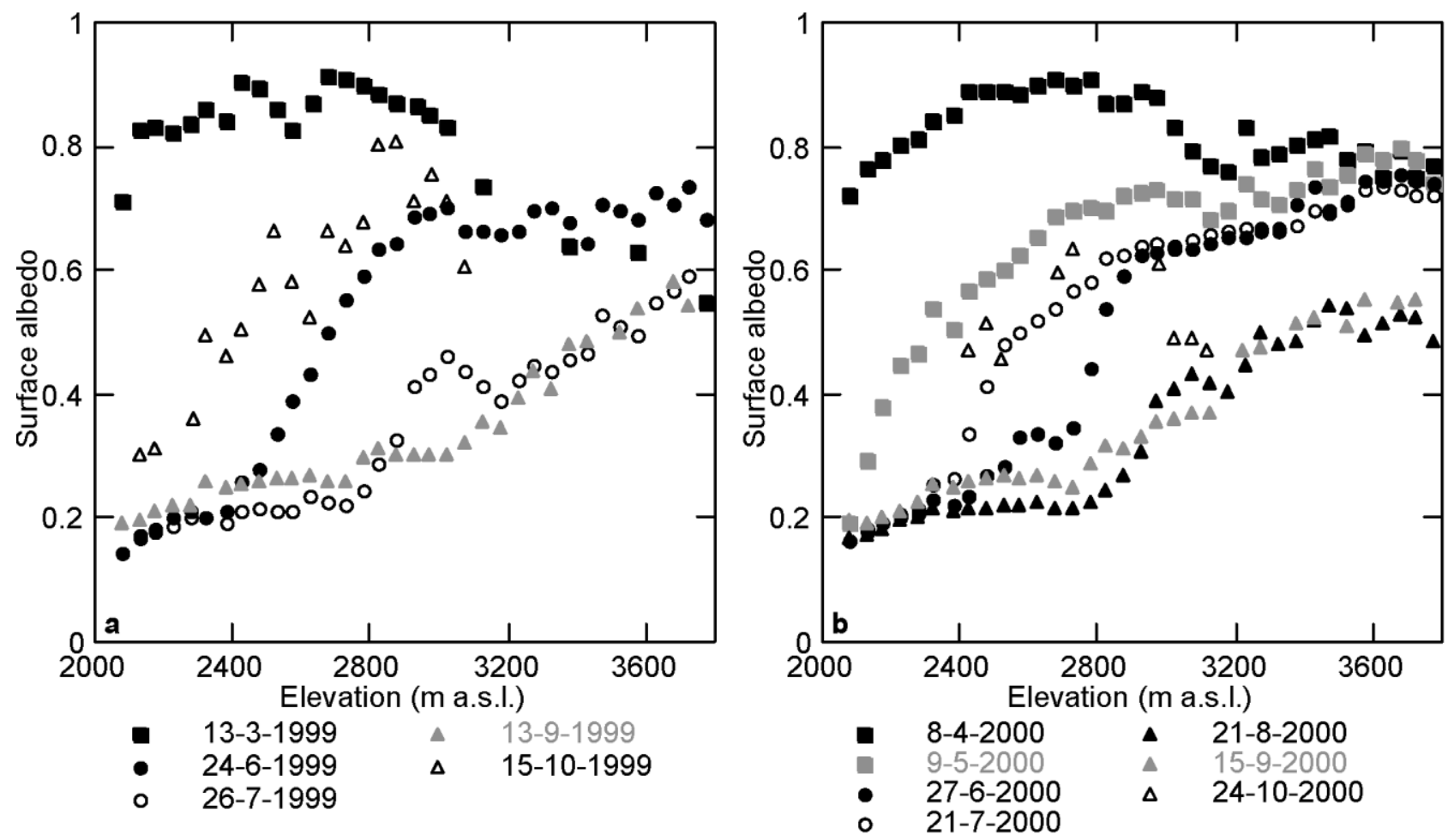

Fig. 6. Mean albedo for $50 \mathrm{~m}$ height intervals derived from 12 Landsat images as function of elevation for 1999 ( a) and 2000 (b). Dates are day-month-year.

for 21 August 2000. For the summer values, the standard deviation is smaller because most of the ablation area is snow-free at that time. Between 27 June and 21 July 2000, the glacier albedo increased by 0.09 owing to a summer snowfall event on 11 July 2000. A sonic ranger located at M1 (see Fig. 1) registered this event. The mean albedos calculated from the October images are probably biased towards lower values because much of the ablation area was omitted due to shading or large solar zenith angles relative to the inclined surface. These pixels mostly represented the higher locations where the topography is steeper (Fig. 2) and the albedos likely higher.

\subsection{Mean albedo over height intervals}

Figure 6 shows satellite-derived glacier albedos averaged over $50 \mathrm{~m}$ height intervals as a function of altitude for all days. We did not take averages for height intervals at which $>50 \%$ of the gridcells were omitted. In March and April, the glacier was totally snow-covered, which is reflected in very high albedos. In May and June, snow gradually melted away, and the snowline moved up-glacier to $2680 \mathrm{~m}$ a.s.l. on 24 June 1999, and $2800 \mathrm{~m}$ a.s.l. on 27 June 2000. (We define the snowline as the altitude at which the albedo is 0.5.) In June, the albedo was about 0.2 at the glacier tongue and $0.65-0.8$ at high elevations. The glacier albedo increased at almost all elevations between 27 June and 21 July 2000, as a result of the summer snowfall event. The snowline reached $3500 \mathrm{~m}$ a.s.l. on 13 September 1999 and $3350 \mathrm{~m}$ a.s.l. on 15 September 2000. Whereas the snowline had moved up-glacier, the ice albedo in the lower parts of the glacier had increased. Between 26 July and 13 September 1999, the average albedo over the glacier tongue (2000-2800 m a.s.l.) increased by about 0.04 . Between 21 August and 15 September 2000, the albedo increased by about 0.03 . Koelemeijer and others (1993) and Brock and others (2000) observed this as well. The latter suggested that glacier albedo can increase due to the removal of debris by rainfall (see section 4.6).

\subsection{Albedo along two centre lines}

We calculated mean albedos along a centre line over Morteratschgletscher and a centre line over Persgletscher (Fig. 1) to investigate differences in the surface albedo of the two glaciers. Means were derived from squares of $3 \times 3$ satellite pixels from five images of the year 2000 and are shown as a function of elevation in Figure 7. The mean centre-line albedos exceed the albedos averaged over $50 \mathrm{~m}$ height intervals (Fig. 6) because the centre lines are located within areas of little debris. The increase in the albedo between 27 June and 21 July due to the snowfall event (on 11 July) shows up in Figure $7 \mathrm{~b}$ and $\mathrm{c}$. All figures show a large scatter in albedo along the centre lines towards higher elevations. These fluctuations are probably associated with the large variation in topography (Fig. 2).

It is striking that the albedo values of Morteratschgletscher often exceed the values of Persgletscher between 2450 and $2700 \mathrm{ma}$ a.s.l. Persgletscher is very crevassed between 2460 and $2600 \mathrm{~m}$ a.s.l. and this partly explains this difference in albedos. Other possible explanations are differences in snow accumulation and melt rate. Morteratschgletscher is located between steep slopes, which probably leads to more snow accumulation caused by snowdrift. Snow-accumulation data from the sonic rangers M2 on Persgletscher and M1 and M3 on Morteratschgletscher for winter 1999/2000 (see Fig. 1) do indeed show a larger increase in snow accumulation between M3 and M1 $(21 \mathrm{~cm}$ $\left.(100 \mathrm{~m})^{-1}\right)$ than between M2 and M1 $\left(18 \mathrm{~cm}(100 \mathrm{~m})^{-1}\right)$. Besides, the steep slopes surrounding Morteratschgletscher cast shadows on the glacier (Klok and Oerlemans, 2002), causing less incoming shortwave radiation on Morteratschgletscher and thus reducing the melt rate. The albedos along 

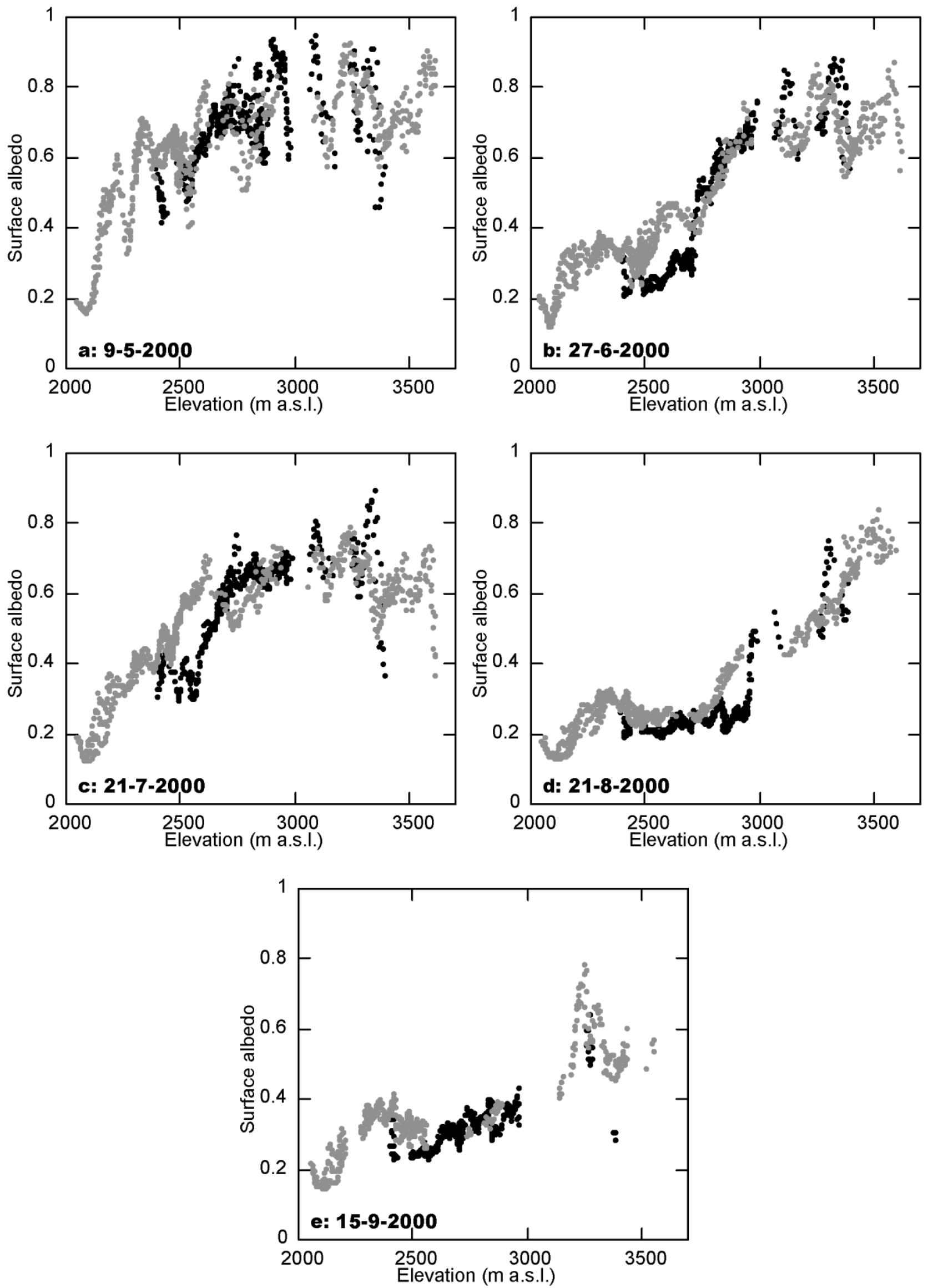

Fig. 7. Mean albedos along the centre line of Morteratschgletscher (grey) and Persgletscher (black) as derived from Landsat images as function of elevation: (a) 9 May 2000; (b) 27 June 2000; (c) 21 July 2000; (d) 21 August 2000; (e) 15 September 2000. The mean albedos are averages of nine pixels. The location of the centre lines is depicted in Figure 1. 


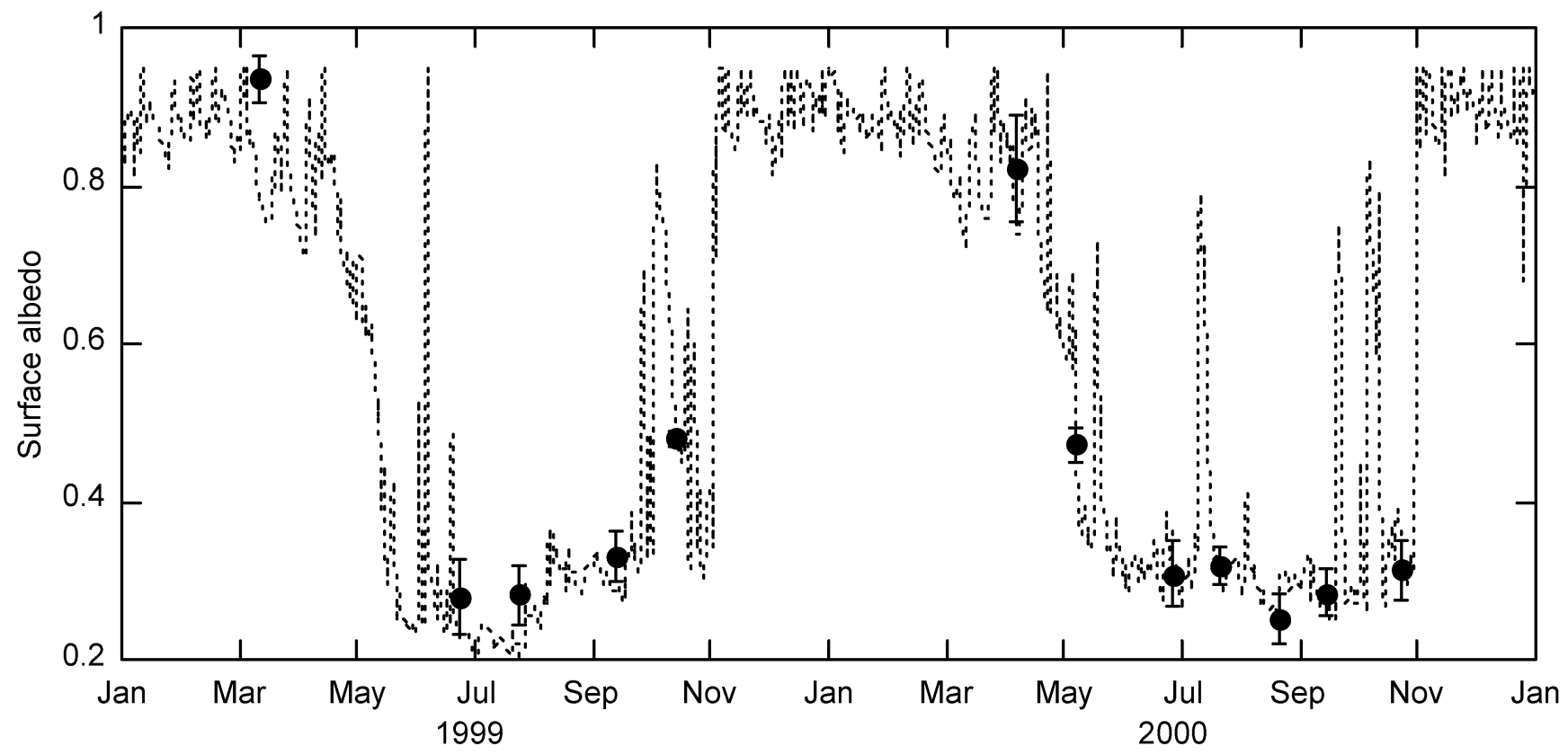

Fig. 8. Mean measured albedo from the automatic weather station at M1 (Fig. 1) at the time of the satellite overpasses (09001000 UTC) (dotted line) and mean satellite-derived albedo (black dots) of nine pixels around M1 for 2 years. The error bars show the standard deviation of the nine pixel values.

the centre lines also reveal a crevassed area located around $2750 \mathrm{~m}$ a.s.l. on Morteratschgletscher.

Looking at the glacier ice areas up to $2900 \mathrm{~m}$ a.s.l. of 21 August and 15 September 2000 (Fig. 7d and e), the ice albedo does not show an increase with altitude. This is often assumed because of increased debris concentrations in lower parts of the glacier (Oerlemans, 1992). We only see an increase in the albedo with elevation between 2000 and $2200 \mathrm{~m}$ a.s.l., and this certainly is associated with differences in the debris amount.

\subsection{Comparison with ground measurements}

An automatic weather station at M1 (Fig. 1) measures incoming and reflected shortwave radiation (Oerlemans and Knap, 1998). Satellite-derived albedos were compared to albedos derived from these radiation measurements for the time the satellite passes over (Fig. 8). The satellite-derived pixels were averaged over a square of nine pixels. The standard deviation of the satellite-derived and measured albedos is 0.07 . On average, satellite-derived albedos exceed the measured surface albedo by 0.03 . However, the satellite-derived albedo of 13 March 1999 is 0.14 larger than the measured albedo. This is likely due to the application of the BRDF parameterizations to albedos outside the range of the BRDF parameterization for snow.

\subsection{Relation between rainfall and an increase in surface albedo}

We calculated an average increase of 0.02 in the glacier albedo for height intervals below $3000 \mathrm{~m}$ a.s.l. between July and September 1999 and estimated this at 0.03 for AugustSeptember 2000 (Fig. 6). For 2000, this increase in glacier albedo towards September is also reflected in Figure 5 by an increase in the mean albedo over the entire ablation area. In addition, Figure 7 shows an increase (of about 0.06) in the ice albedo along the centre line of Morteratschgletscher, and the satellite-derived surface albedo for Ml in- creased by 0.09 between July and September 1999 and by 0.04 from August to September 2000 (Fig. 8). Data of the sonic ranger located at $\mathrm{M} 1$ prove that this feature cannot be explained by summer snowfall events only. Brock and others (2000) suggested that rainfall removes debris from the glacier, resulting in an increasing albedo during the summer season.

To test this hypothesis, we compared daily rainfall rates with the change in albedo between two days measured by the automatic weather station at M1 (Fig. 1). Albedo measurements from this station for the years 1996-2000 also demonstrated that the albedo at M1 increases over JulySeptember, on average by 0.08 . This can be seen in Figure 8 for 1999, but this increase does not show up for 2000. We used precipitation data from Bernina Curtinatsch, located $5 \mathrm{~km}$ northeast of Morteratschgletscher at $2095 \mathrm{~m}$ a.s.l., for July-September 1996-2000. Summer snowfall events were excluded from the dataset. Analysis of the daily rainfall data and changes in daily albedo proved that during $83 \%$ of the 82 days on which daily precipitation exceeded $5 \mathrm{~mm}$, an increase in the albedo was measured. The mean increase was 0.03. This supports the notion that rainfall washes away debris from the glacier surface and that this leads to an increase in the glacier albedo. Therefore, rainfall may have caused the increase in surface albedo towards September shown by the satellite data.

\section{SUMMARY AND CONGLUSIONS}

This research investigated the spatial and temporal variation in the surface albedo of a glacier with a very rugged accumulation area by studying a large number of Landsat TM and ETM+ images. Satellite data of Morteratschgletscher for 12 days in 1999 and 2000 were used. We studied the retrieval method thoroughly and tried to consider all important processes that influence the relationship between the signal received by the satellite and the surface albedo within the retrieval method. We took into account the aniso- 
tropy of both ice and snow, which to our knowledge has not been attempted before. The good agreement between Landsat-derived albedos and albedo measurements from an automatic weather station on the glacier tongue leads us to believe that the retrieval method generally generates accurate estimates of the glacier albedo.

However, the retrieval method does not perform well for snow-covered areas with high albedos. We base this conclusion on very large satellite-derived albedos $(>0.95)$ for spring. This is likely due to the correction for anisotropy since we sometimes applied the BRDF parameterizations for snow to surface albedos, particularly high albedos, that fell beyond the validity ranges of these parameterizations. We think that the application of the BRDF parameterizations may have led to errors of up to 0.07 in these derived surface albedos. The mean anisotropic correction ranged up to 0.10 for satellite-derived surface albedos of Morteratschgletscher, depending on the solar zenith angle, the surface type and the wavelength band.

Also, for rugged areas with a large variation in surface slope and aspect, the uncertainty in the surface albedo appears to be large. We derive this conclusion from observations for areas with low satellite-derived surface albedos at high altitudes and a larger scatter in satellite-derived albedos at high altitudes. It is associated with the estimation of slope and aspect of each pixel, influencing the correction for topographic effects (Equation (3)) and anisotropy (Equation (4)). Mean surface albedo errors of up to 0.07 can be expected for individual pixels at altitudes $>3000 \mathrm{~m}$ a.s.l. owing to the inaccuracy of the image geolocation, which results in a different topography for each satellite pixel.

Errors related to the uncertainties in atmospheric composition and in the narrow-to-broadband conversion were small. In order to improve the retrieval method, it would be useful to determine BRDFs for a wider range of surface albedos and solar zenith angles. However, we expect that an accurate assessment of albedos for areas with a large variation in slope will remain difficult.

The results show that the ice of the glacier tongue is characterized by longitudinal bands with a more-or-less constant albedo. A band in the middle is flanked on both sides by bands of lower albedo (0.15) due to debris. The lateral variation in ice albedo appears to exceed the altitudinal variation in ice albedo. From the results, we cannot conclude that the ice albedo shows a dependence on altitude. This has also been demonstrated by Brock and others (2000) for Haut Glacier d'Arolla, Switzerland, and by Greuell and others (1997) for Pasterzenkees, Austria, but, for Hintereisferner, Koelemeijer and others (1993) found the ice albedo increasing with elevation. During the summer, the satellite-derived albedos of the glacier ice rose by about 0.06 , which is most likely associated with rainfall washing away debris. Albedo measurements made on the glacier during 1996-2000 and precipitation data from a weather station near Morteratschgletscher revealed that the daily mean albedo increased on $83 \%$ of all summer days with $>5 \mathrm{~mm}$ of rainfall.

Concerning the modelling of the albedo within energyand mass-balance models, we conclude that for Morteratschgletscher the glacier ice albedo should not be parameterized as a function of altitude. We also found that the variation in the ice albedo is mainly caused by bands with high debris concentrations flanking a band of clean ice in the middle of the glacier tongue. However, if we were to prescribe lower ice albedos for these areas within the massbalance model, we would possibly need to include the isolating effect of the debris cover to prevent overestimation of the melt rate. Lastly, we could prescribe a lower ice albedo for crevassed areas and make the ice albedo a function of summer rainfall. As the changes in albedo due to these effects are small, we think that they have little impact on the mass-balance calculation. In a future project, we will use the satellite-derived albedos of this study to validate the current albedo scheme used in the mass-balance model of Morteratschgletscher (Klok and Oerlemans, 2002).

\section{ACKNOWLEDGEMENTS}

We would like to thank W. H. Knap and C. H. Reijmer for helping us with the albedo retrieval method and commenting on an earlier version of this paper. We are grateful to A. Souren who corrected the English. We also thank the two referees and the Scientific Editor, H. Rott, for their useful comments.

\section{REFERENCES}

Arnold, N. S., I. C. Willis, M. J. Sharp, K. S. Richards and W. J. Lawson. 1996. A distributed surface energy-balance model for a small valley glacier. I. Development and testing for Haut Glacier d'Arolla, Valais, Switzerland. F. Glaciol., 42(140), 77-89.

Brock, B.W., I. C. Willis and M. J. Sharp. 2000. Measurement and parameterization of albedo variations at Haut Glacier d'Arolla, Switzerland. F. Glaciol., 46(155), 675-688.

Bundesamt für Landestopographie. 1991. Landeskarte der Schweiz. (Scale 1:25000.) Wabern, Bundesamt für Landestopographie.

De Ruyter deWildt, M. S., J. Oerlemans and H. Björnsson. 2002. A method for monitoring glacier mass balance using satellite albedo measurements: application to Vatnajökull, Iceland. f. Glaciol., 48(161), 267-278.

Dozier, J. and J. Frew. 1990. Rapid calculation of terrain parameters for radiation modeling from digital elevation data. IEEE Trans. Geosci. Remote Sensing, GE-28(5), 963-969.

Greuell, W. 2000. Melt-water accumulation on the surface of the Greenland ice sheet: effect on albedo and mass balance. Geogr. Ann., 82A(4), 489-498.

Greuell, W. and M. S. de Ruyter de Wildt. 1999. Anisotropic reflection of melting glacier ice: measurements and parameterizations. Remote Sensing Environ., 70(3), 265-277.

Greuell, W., W. H. Knap and P. C. Smeets. 1997. Elevational changes in meteorological variables along a mid-latitude glacier during summer. $\mathcal{F}$. Geophys. Res., 102 (D22), 25,941-25,954.

Klok, E. J and J. Oerlemans. 2002. Model study of the spatial distribution of the energy and mass balance of Morteratschgletscher, Switzerland. $\mathcal{F}$. Glaciol., 48(163), 505-518.

Knap, W. H. and J. Oerlemans. 1996. The surface albedo of the Greenland ice sheet: satellite-derived and in situ measurements in the Søndre Strømfjord area during the 1991 melt season. F. Glaciol., 42 (141), 364-374.

Knap, W. H., B. W. Brock, J. Oerlemans and I. C. Willis. 1999a. Comparison of Landsat TM-derived and ground-based albedos of Haut Glacier d'Arolla, Switzerland. Int. F. Remote Sensing, 20(17), 3293-3310.

Knap, W. H., G. H. Reijmer and J. Oerlemans. 1999b. Narrowband to broadband conversion of Landsat TM glacier albedos. Int. 7. Remote Sensing, 20(10), 2091-2110.

Koelemeijer, R., J. Oerlemans and S. Tjemkes. 1993. Surface reflectance of Hintereisferner, Austria, from Landsat 5 TM imagery. Ann. Glaciol., 17, $17-22$.

Koks, M. 2001. Anisotropic reflection of radiation by melting snow. Landsat TM bands 2 and 4. (M.Sc. thesis, Universiteit Utrecht. Instituut voor Marien en Atmosferisch Onderzoek Utrecht (IMAU).)

Li Xin, T. Koike and Cheng Guodong. 2002. Retrieval of snow reflectance from Landsat data in rugged terrain. Ann. Glaciol., 34, 31-37.

Markham, B. L. and J. L. Barker. 1985. Spectral characterization of the LANDSAT Thematic Mapper sensors. Int. 7. Remote Sensing, 6 (5), 697-716.

National Aeronautics and Space Administration (NASA). 2001. Landsat-7 science data users' handbook. Greenbelt, MD, U.S. National Aeronautics and Space Administration. Goddard Space Flight Center. (http:// ltpwww.gsfc.nasa.gov/IAS/handbook/handbook.toc.html) 
Oerlemans, J. 1992. Climate sensitivity of glaciers in southern Norway: application of an energy-balance model to Nigardsbreen, Hellstugubreen and Alfotbreen. 7. Glaciol., 38(129), 223-232.

Oerlemans, J. and W. H. Knap. 1998. A l year record of global radiation and albedo in the ablation zone of Morteratschgletscher, Switzerland. F. Glaciol., 44(147), 231-238.

Paterson, W. S. B. 1994. The physics of glaciers. Third edition. Oxford, etc., Elsevier.

Proy, C., D. Tanré and P.Y. Deschamps. 1989. Evaluation of topographic effects in remotely sensed data. Remote Sensing Environ., 30, 21-32.

Reijmer, C. H., W. H. Knap and J. Oerlemans. 1999. The surface albedo of the Vatnajökull ice cap, Iceland: a comparison between satellite-derived and ground-based measurements. Boundary-Layer Meteorol., 92(1), 125-144.

Richter, R. 1998. Correction of satellite imagery over mountainous terrain. Appl. Opt., 37(18), 4004-4015.

Sandmeier, S. and K. I. Itten. 1997. A physically-based model to correct atmospheric and illumination effects in optical satellite data of rugged terrain. IEEE Trans. Geosci. Remote Sensing, GE-35(3), 708-717.
Slingo, A. and H. M. Schrecker. 1982. On the shortwave radiative properties of stratiform water clouds. Q. F. R. Meteorol. Soc., 108, 407-426.

Stroeve, J., A. Nolin and K. Steffen. 1997. Comparison of AVHRR-derived and in situ surface albedo over the Greenland ice sheet. Remote Sensing Environ., 62(3), 262-276.

Teillet, P. M., J. L. Barker, B. L. Markham, R. R. Irish, G. Fedosejevs and J. C. Storey. 2001. Radiometric cross-calibration of the Landsat-7 ETM+ and Landsat-5 TM sensors based on tandem data sets. Remote Sensing Environ., 78, 39-54.

Vermote, E., D. Tanré, J. L. Deuzé, M. Herman andJ. J. Morcette. 1997. Second simulation of the satellite signal in the solar spectrum: an overview. IEEE Trans. Geosci. Remote Sensing, GE-35(3), 675-686.

Warren, S. G., R. E. Brandt and P. O. Hinton. 1998. Effect of surface roughness on bidirectional reflectance of Antarctic snow. 7. Geophys. Res., 103 (E11), 25,789-25,805.

MS received 6 January 2003 and accepted in revised form 15 July 2003 